удк 336.767.017.2

А. А. Тимофеева

Байкальский государственный университет, г. Иркутск, Российккая Федерация

\title{
СОВЕРШЕНСТВОВАНИЕ ПРОЦЕССА ДОВЕРИТЕЛЬНОГО УПРАВЛЕНИЯ ПЕНСИОННЫМИ НАКОПЛЕНИЯМИ
}

\begin{abstract}
АНнотАция. В статье рассмотрены некоторые аспекты взаимодействия управляющих компаний с Пенсионным фондом России и Центральным банком Российской Федерации на этапе заключения договоров доверительного управления накопительной пенсией. Выявлены противоречия, существующие в документальном сопровождении процесса доверительного управления. Предложено составление и применение на практике управляющими компаниями единого документа, который должен содержать постановку цели осуществления деятельности по доверительному управлению пенсионными накоплениями. Предполагается, что цель деятельность по доверительному управлению пенсионными накоплениями должна быть сформулирована исходя из интересов конечных пользователей (застрахованных лиц). При этом главным условием должно выступать обеспечение сохранности пенсионных накоплений на приемлемом для застрахованного лица уровне. Для достижения цели управляющим компаниям рекомендовано формирование трех различных по уровню риска инвестиционных портфелей: безрисковый, среднерисковый и рисковый.

кЛюЧЕВЫЕ СЛОВА. Доверительное управление; управляющая компания; накопительная пенсия; сохранность пенсионных накоплений.

ИНФОРМАЦИЯ О СТАТЬЕ. Дата поступления 22 февраля 2016 г.; дата принятия к печати 6 марта 2016 г.; дата онлайн-размещения 29 марта 2016 г.
\end{abstract}

\author{
A. A. Timofeyeva \\ Baikal State University, \\ Irkutsk, Russian Federation
}

\section{IMPROVING THE PROCESS OF TRUST MANAGEMENT OF PENSION ASSETS}

\begin{abstract}
The article considers some cooperation aspects for management companies with Russia's Pension Fund and Central Bank of the Russian Federation at the stage of executing agreements on funded pension trust management. It identifies contradictions existing in documentation of the trust management process. It offers compiling and applying by management companies in practice a single document which must contain a goal setting for performing activities in terms of trust management of pension assets. It is assumed that the activity goal in terms of trust management of pension assets must be developed according to the interests of the final user ( the insured).

KEYWORDS. Asset management, property management company, funded pension, preservation pension savings.

ARTICLE INFO. Received February 22, 2016; accepted March 6, 2016; available online March 29, 2016.
\end{abstract}

Результаты инвестирования пенсионных накоплений свидетельствуют о возможности получения различных значений показателя «доходность» (табл. 1). Эффективность управления пенсионными накоплениями определяется множеством факторов. Научная литература по этому поводу многопланова. В целом, при изучении роли факторов, влияющих на доходность инвестиционного портфеля, принято говорить о двух основных подходах. Согласно первому подходу доходность инвестиционного портфеля объясняется распределением активов, а в соответствии со вторым - доходность зависит от волатильности самого рынка, т. е. рыночных колебаний, а не от усилий управляющих компаний $[1$, с. 27]. Однако не смотря на существующие подходы, сле-

(C) A. А. Тилофеева, 2016

\section{Baikal Research Journal}

электронный научный журнал Байкальского государственного университета 
дует учитывать тот факт, что управляющие компании осуществляют свою деятельность под влиянием абсолютно идентичных внешних условий, в связи с чем важное значение приобретает эффективно организованный и осуществляемый в соответствии с внутренними документами процесс доверительного управления пенсионными накоплениями в каждой управляющей компании. Наличие единого документа, содержащего основные правила осуществления деятельности по доверительному управлению пенсионными накоплениями, по мнению автора, является способом, позволяющим повысить эффективность осуществления данного вида деятельности.

Таблица 1

Доходность инвестирования пенсионных накоплений, \%

\begin{tabular}{|l|r|r|r|r|}
\hline \multirow{2}{*}{ Год } & \multicolumn{2}{|c|}{ Государственная управляющая компания } & \multicolumn{2}{c|}{$\begin{array}{c}\text { Доходность, полученная частной } \\
\text { управляющей компанией }\end{array}$} \\
\cline { 2 - 5 } & $\begin{array}{c}\text { Инвестиционный порт- } \\
\text { фель государствнных } \\
\text { ценных бумаг }\end{array}$ & $\begin{array}{c}\text { Расширенный } \\
\text { инвестиционный } \\
\text { портфель }\end{array}$ & Максимальная & Минимальная \\
\hline 2009 & 5,72 & 9,52 & 110,48 & 7,56 \\
\hline 2010 & 8,17 & 7,62 & 33,21 & 7,52 \\
\hline 2011 & 5,90 & 5,47 & 7,69 & $-17,83$ \\
\hline 2012 & 8,47 & 9,21 & 13,51 & $-0,66$ \\
\hline 2013 & 6,90 & 6,71 & 9,94 & $-6,03$ \\
\hline 2014 & $-2,05$ & 2,68 & 7,49 & $-9,89$ \\
\hline III кв. 2015 & 15,81 & 12,17 & 24,34 & 1,27 \\
\hline
\end{tabular}

Составлено по данным Пенсионного Фонда Российской Федерации. URL : www.pfrf.ru.

Одним из условий для заключения Пенсионным фондом России (ПФР) с управляющей компанией договора доверительного управления пенсионными накоплениями является наличие у последней лицензии на осуществление деятельности по управлению инвестиционными фондами, паевыми инвестиционными фондами, негосударственными пенсионными фондами. При этом требования, предъявляемые к лицензиату для получения данной лицензии, не содержат указание на необходимость предоставления в регистрирующий орган какого-либо внутреннего регламента (правил) осуществления деятельности по доверительному управлению. Однако п. 19.2 ст. 12 Федерального закона «Об инвестировании средств для финансирования накопительной пенсии в Российской Федерации» от 24 июля 2002 г. № 111-Ф3 (далее - ФЗ № 111-ФЗ) уточняет обязанности управляющей компании, осуществляющей деятельность по доверительному управлению пенсионными накоплениями, в частности, в нем зафиксирована необходимость принятия и соблюдения Внутреннего регламента совершения операций со средствами пенсионных накоплений, отражающего особенности деятельности по доверительному управлению средствами пенсионных накоплений (далее - Внутренний регламент). Указанный документ подлежит согласованию с Центральным банком Российской Федерации (ЦБ РФ) и должен содержать положения, определяющие:

1. Порядок принятия и исполнения решений по инвестированию средств пенсионных накоплений.

2. Порядок осуществления контроля за рисками при совершении операций по инвестированию средств пенсионных накоплений.

3. Порядок обеспечения защиты служебной информации об операциях по инвестированию средств пенсионных накоплений от несанкционированного доступа (см. п. 19.2 ст. 2 ФЗ № 111-ФЗ).

Принятым Порядком согласования внутреннего регламента совершения операций со средствами пенсионных накоплений, отражающим особенности деятельно-

\section{Baikal Research Journal}


сти по доверительному управлению средствами пенсионных накоплений, утвержденным приказом Федеральной службы по финансовым рынкам России от 29 марта

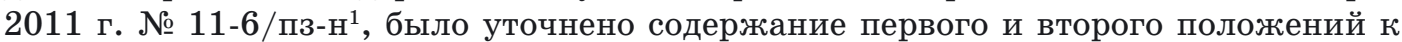
Внутреннему регламенту, определенных в ФЗ № 111-ФЗ, а именно:

1. Порядок принятия и исполнения решений по инвестированию средств пенсионных накоплений, содержащий следующие разделы:

- организационная структура доверительного управления средствами пенсионных накоплений (функции, полномочия и обязанности сотрудников и структурных подразделений управляющей компании);

- порядок осуществления инвестирования средств пенсионных накоплений);

- порядок внесения изменений и дополнений во внутренний регламент.

2. Порядок осуществления контроля за рисками при совершении операций по инвестированию средств пенсионных накоплений, включающий разделы:

- ограничение рисков по операциям доверительного управления -требования к операциям по инвестированию средств пенсионных накоплений;

- контроль - контрольные функции уполномоченных сотрудников и структурных подразделений управляющей компании при осуществлении операций по инвестированию средств пенсионных накоплений.

Таким образом, можно заметить, что при составлении Внутреннего регламента основное внимание уделяется двум составляющим деятельности по доверительному управлению: инвестированию пенсионных накоплений и контролю. Вместе с тем, сам процесс доверительного управления может быть рассмотрен как совокупность следующих четырех этапов:

1. Составление инвестиционной декларации.

2. Инвестирование пенсионных накоплений.

3. Оплата расходов, связанных с управлением пенсионными накоплениями, и начисление вознаграждения управляющей компании.

4. Контроль [2].

Кроме того, Внутренний регламент - это документ, необходимость составления и согласования которого в ЦБ РФ прописана в функциях управляющих компаний. Это означает, что Внутренний регламент вторичен по отношению к договору доверительного управления, заключаемому ПФР с управляющими компаниями.

В то же время существует перечень так называемых «первичных документов», т. е. документов, которые должны быть представлены управляющей компанией до заключения с нею ПФР договора. Согласно постановлению Правительства РФ от 10 сентября 2010 г. № $708^{2}$ в число этих документов входят:

- размеры предлагаемых участником размещения заказа вознаграждения и необходимых расходов управляющей компании по инвестированию средств пенсионных накоплений;

- инвестиционная декларация, соответствующая требованиям ст. 27 ФЗ № 111-ФЗ.

Отметим, что эти два документа есть отражение организации работы управляющей компании в рамках первого и третьего этапов доверительного управления средствами пенсионных накоплений, выделенных нами ранее.

${ }^{1}$ Об утверждении Порядка согласования внутреннего регламента совершения операций со средствами пенсионных накоплений, отражающего особенности деятельности по доверительному управлению средствами пенсионных накоплений [Электронный ресурс]: приказ Федеральной службы по финансовым рынкам России от 29 марта 2011 г. № 11-6/пз-н // СПС «КонсультантПлюс» .

${ }^{2}$ Об утверждении Правил организации и проведения конкурса на заключение договоров доверительного управления средствами пенсионных накоплений с Пенсионным фондом Российской Федерации и Правил продления договоров доверительного управления средствами пенсионных накоплений, заключенных с Пенсионным фондом Российской Федерации : постановление Правительства РФ от 10 сентября 2010 г. № 708.

\section{Baikal Research Journal}

электронный научный журнал Байкальского государственного университета 
Наличие нескольких документов, регламентирующих порядок организации и осуществления отдельных этапов единого процесса доверительного управления пенсионными накоплениями, по мнению автора, способно иметь негативные последствия по ряду причин.

Во-первых, это затрудняет работу управляющих компаний при управлении пенсионными накоплениями, так как требует дополнительной координации четырех, по сути разрозненных этапов процесса доверительного управления, что может привести к ухудшению показателей их деятельности, в том числе доходности, следовательно, отрицательно повлияет на размер накопительной пенсии будущих пенсионеров.

Во-вторых, такая ситуация не способствует получению ПФР и ЦБ РФ объективной информации о деятельности по доверительному управлению, как целостного и единого процесса, в каждой отдельной управляющей компании. Это может привести к допущению к управлению пенсионными накоплениями управляющих компаний, не способных обеспечить надлежащее доверительное управление, что усугубляется также, во-первых, тем фактом, что договоры доверительного управления заключаются ПФР со всеми управляющими компаниями, которые отобраны по результатам конкурса, во-вторых, тем, что Внутренний регламент регистрируется в ЦБ РФ после заключения договора доверительного управления средствами пенсионных накоплений управляющей компанией с ПФР.

В связи с изложенным требуется составление и применение управляющими компаниями на практике единого документа - Регламента осуществления деятельности по доверительному управлению пенсионными накоплениями, содержащему описание организации и осуществления действий управляющей компании на всех из четырех этапах процесса доверительного управления. Данный документ должен содержать цель осуществления деятельности по доверительному управлению пенсионными накоплениями. В настоящее время она не закреплена в законодательстве Российской Федерации. В ст. 27 ФЗ № 111-ФЗ определена лишь цель инвестирования пенсионных накоплений - прирост данных средств. Однако, как было показано ранее, инвестирование есть лишь часть процесса доверительного управления. Перенос цели инвестирования пенсионных накоплений на деятельность по доверительному управлению в том виде, в котором она зафиксирована законодателем, не возможен, так как она не учитывает интересы конечных пользователей данных средств, которыми являются застрахованные лица [3, с. 240]. По нашему мнению, цель осуществления деятельности по доверительному управлению пенсионными накоплениями должна быть сформулирована исходя из целей застрахованных лиц и основана на уровне риска, приемлемом для них.

Социологические опросы, проводившиеся в последние несколько лет, свидетельствовали о необходимости обеспечения сохранности пенсионных накоплений. Так, о гарантировании пенсионных накоплений, как ключевом условии доверия к пенсионной системе, говорили $2 / 3$ опрошенных [4, с. 53]. Опыт зарубежных стран, развивающих свои пенсионные системы по накопительному принципу, также подтверждал важность внедрения механизма сохранности пенсионных накоплений (в том числе путем введения института страхования на пенсионный рынок) $[5$, с. $70 ; 6$, с. $52 ; 7$, с. $63 ; 8$, с. 82$]$.

Так, например, в 2000 г. Правительством Китая был создан Национальный фонд социальной безопасности (NSSF - National Social Security Fund) в качестве пенсионного фонда последней инстанции. Смысл создания фонда - обеспечение стабильности пенсионной системы Китая в будущем [9, с. 52].

В соответствии с Пенсионным законом 2004 г. в Великобритании был создан и начал работать с 6 апреля 2005 г. Фонд защиты пенсии, целью которого является выплата компенсаций участникам профессиональных пенсионных схем с установленным размером пенсии или участникам смешанного типа схем с элементом установленного

\section{Baikal Research Journal}

электронный научный журнал Байкальского государственного университета 
размера пенсии в случае юридически определенной неплатежеспособности работодателя по состоянию на 6 апреля 2005 г. или после этой даты, когда недостаточные активы пенсионной схемы не покрывают уровень компенсации [10]. Данный фонд финансируется непосредственно первоначальными взносами и, косвенно, административными сборами, которые устанавливаются госсекретарем по труду и пенсиям ${ }^{3}$.

Успешным примером обязательного государственного страхового пенсионного института является Корпорация гарантий пенсионных выплат в США, основная задача которой - обеспечение гарантированных пенсий участникам пенсионных программ компаний, признанных финансово несостоятельными [11, с. 218].

Функционирование системы гарантирования пенсионных накоплений в Российской Федерации стало возможным в связи с принятием Федерального закона «О гарантировании прав застрахованных лиц в системе обязательного пенсионного страхования Российской Федерации при формировании и инвестировании средств пенсионных накоплений, установлении и осуществлении выплат за счет средств пенсионных накоплений» от 28 декабря 2013 г. № 422-ФЗ. В целях повышения эффективности института накопительных пенсий государство сделало серьезный шаг в сторону улучшения организационной структуры, управляемости, надежности и прозрачности процессов. Была проделана значительная работа по акционированию пенсионных фондов и вступлению их в систему гарантирования. Государство создало специальную систему страхования пенсионных накоплений, которая позволяет при любых обстоятельствах выплатить гражданам номинальную сумму пенсионных взносов на накопительную пенсию [12, с. 142]. Сегодня Агентство по страхованию вкладов гарантирует возмещение всех взносов и средств, отраженных на счете накопительной пенсии застрахованного лица, за исключением накопленного инвестиционного дохода.

Представляется, что понятие «сохранность» может быть различным для разных инвесторов. Основным фактором при определении сохранности пенсионных накоплений в каждом конкретном случае будет считаться уровень риска, приемлемый для застрахованного лица. Если для одного застрахованного лица недопустима ситуация, когда сумма взносов, находящаяся на его индивидуальном счете в ПФР, по итогам доверительного управления будет уменьшена, то другой застрахованный согласен принять на себя больший риск и соответствующую ему неограниченную доходность.

Исходя из чего следует, что цели застрахованных лиц могут не совпадать и являться требованиями к обеспечению управляющими компаниями сохранности на номинальном или реальном уровне, либо не предъявляться вообще. Таким образом, можно выделить три группы застрахованных лиц:

- консервативные, предъявляющие требование к обеспечению реальной сохранности;

- умеренно-агрессивные, в отношении которых действует понятие номинальной сохранности;

- агрессивные, не предъявляющие требование к сохранности пенсионных накоплений.

В связи с этим, по нашему мнению, в качестве цели осуществления деятельности по доверительному управлению пенсионными накоплениями должно быть обозначено - обеспечение сохранности пенсионных накоплений на приемлемом для застрахованного лица уровне.

Для достижения поставленной цели рекомендуется формирование управляющими компаниями трех различных по уровню риска инвестиционных портфелей (табл. 2) для каждой группы застрахованных лиц:

- безрисковый - для консервативных застрахованных лиц;

${ }^{3}$ По материалам Департамента труда и пенсий Великобритании / Фонд защиты пенсий // Пенсионные фонды и инвестиции. 2008. № 1. С. 74-80.

\section{Baikal Research Journal}

электронный научный журнал Байкальского государственного университета 
- среднерисковый - для умеренно-агрессивных застрахованных лиц;

- рисковый - для агрессивных застрахованных лиц.

Таблица 2

Характеристика инвестиционных портфелей, формируемых по уровнял риска

\begin{tabular}{|c|c|c|c|}
\hline Показатель & Рисковый & Среднерисковый & Безрисковый \\
\hline $\begin{array}{l}\text { Сохранность пенсионных нако- } \\
\text { плений }\end{array}$ & Не обеспечивается & Номинальная & Реальная \\
\hline $\begin{array}{l}\text { Доходность пенсионных накопле- } \\
\text { ний: } \\
\text { минимальная } \\
\end{array}$ & Не гарантируется & $0 \%$ & \multirow{2}{*}{$\begin{array}{c}\text { Совпадает с офи- } \\
\text { циальным показа- } \\
\text { телем инфляции в } \\
\text { стране }\end{array}$} \\
\hline максимальная & Не ограничивается & Не ограничивается & \\
\hline Необходимость создания резерва & Нет & Да & Да \\
\hline $\begin{array}{l}\text { Источники формирования } \\
\text { резерва: } \\
\quad \text { страховые взносы } \\
\end{array}$ & - & + & + \\
\hline $\begin{array}{l}\text { сумма, рассчитанная пропор- } \\
\text { ционально превышению доход- } \\
\text { ности по портфелю от гаранти- } \\
\text { руемого результата }\end{array}$ & - & - & + \\
\hline
\end{tabular}

Предполагается, что застрахованные лица, выбравшие высокорисковый инвестиционный портфель, принимают присущие данному портфелю риски: курсовой и дефолтный. При этом суммы на индивидуальных счетах застрахованных лиц в системе персонифицированного учета ПФР могут меняться как в большую, так и в меньшую сторону в зависимости от доходности, полученной по портфелю. Таким образом, понятие сохранности в отношении пенсионных накоплений, составляющих высокорисковый портфель, не применяется. Пенсионные накопления в этом случае не защищены ни от абсолютного, ни от относительного обесценения. Однако в случае доходности по портфелю выше уровня инфляции в стране, застрахованные лица, выбравшие данный вид портфеля, как премию за риск, получат максимальный прирост пенсионных накоплений, по сравнению с застрахованными лицами, выбравшими другие инвестиционные портфели. Как видим, ни максимальное, ни минимальное значение доходности по инвестиционному портфелю с высоким уровнем риска не ограничено.

Доверительное управление средствами, составляющими среднерисковый и безрисковый инвестиционные портфели, должно сопровождаться обеспечением сохранности пенсионных накоплений. Поскольку портфели имеют разные уровни риска, то и сохранность пенсионных накоплений, составляющих эти виды портфелей, должна быть обеспечена по ним в разных объемах.

По среднерисковому портфелю сохранность пенсионных накоплений обеспечивается в отношении сумм, изначально поступивших из ПФР (речь идет о так называемой номинальной сохранности, но не о реальной). В случае отсутствия прироста стоимости чистых активов инвестиционного портфеля со средним уровнем риска суммы на индивидуальных счетах застрахованных лиц, выбравших данный портфель, не увеличатся. Если же управляющая компания декларировала отрицательный результат, то убыток должен быть покрыт в части средств, недостающих до суммы, изначально поступившей в доверительное управление.

Представляется, что поступления на индивидуальные счета застрахованных лиц в системе персонифицированного учета ПФР, выбравших безрисковый портфель, должны коррелировать с уровнем инфляции в стране. Если доходность, полученная управляющей компанией при управлении данным портфелем, ниже уровня инфляции, то недостающая сумма должна быть компенсирована. Показатель доходности, применяемый для безрискового инвестиционного портфеля, может при-

\section{Baikal Research Journal}


нимать лишь одно значение - равное уровню инфляции в стране. Если доходность портфеля по итогам доверительного управления превысила уровень инфляции, то сумма, рассчитанная пропорционально превышению доходности по портфелю над инфляцией в стране, должна быть направлена в резервный фонд управляющей компании, специально созданный ею в этих целях. Помимо этого, обеспечение сохранности в отношении пенсионных накоплений, составляющих среднерисковый и безрисковый инвестиционные портфели, должно осуществляться за счет резервирования части пенсионных накоплений, изначально поступивших от застрахованных лиц и составляющих соответствующие портфели. Отчисления в резервный фонд по данным портфелям должны производиться управляющими компаниями после обработки заявлений о выборе портфелей, но до начала процесса доверительного управления. Логично предположить, что процент отчислений по безрисковому портфелю должен быть большим по сравнению с портфелем среднего уровня риска.

Таким образом, внедрение трех различных по уровню риска инвестиционных портфелей будет способствовать:

- обеспечению лучших показателей деятельности по доверительному управлению пенсионными накоплениями для каждой группы застрахованных лиц в соответствии с заявленными ожиданиями;

- автоматическому перераспределению рыночных рисков, возникающих при инвестировании пенсионных накоплений, между застрахованными лицами и управляющими компаниями.

\section{Список использованной литературы}

1. Эффективность управления пенсионными накоплениями: теоретические подходы и эмпирический анализ / А. Абрамов, А. Радыгин, М. Чернова, К. Акшенцева // Вопросы экономики. - 2015. - № 7. - С. 26-44.

2. Тимофеева А. А. К вопросу о деятельности по доверительному управлению целевым капиталом [Электронный ресурс] / А. А. Тимофеева // Известия Иркутской государственной экономической академии (Байкальский государственный университет экономики и права). - 2015. - T. 6, № 2. - DOI : 10.17150/2072-0904.2015.6(2).1.

3. Тимофеева А. K вопросу о законодательных ограничениях при инвестировании средств пенсионных накоплений / А. Тимофеева // Материалы 68-й ежегодной научной конференции профессорско-преподавательского состава и докторантов, 20-й научной конференции аспирантов и 70-й научной конференции студентов и магистрантов. - Иркутск : Изд-во БГУЭП, 2009. - Ч. 1. - С. 238-243.

4. Дмитриев М. Из пустого не льется / М. Дмитриев // Вестник НАУФОР. - 2010. № 5. - С. 52-54.

5. Лельчук А. Л. Почему Россия не Швеция - к вопросу о пенсионной реформе / А. Л. Лельчук // Пенсионные фонды и инвестиции. - 2008. - № 1. - С. 68-72.

6. Ломтатидзе О. В. Проблема защиты прав частных инвесторов в системе регулирования финансового рынка / О. В. Ломтатидзе // Финансы и кредит. - 2011. — № 2. - С. 50-55.

7. Хмыз О. Реформирование системы пенсионного обеспечения в Чехии / О. Хмыз // Финансы. - 2010. - № 1. - С. 56-66.

8. Бровчак С. В. Пенсионное обеспечение в Греции и России / С. В. Бровчак // Финансы и кредит. - 2011. - № 19. - С. 81-84.

9. Пензин К. Российско-китайские параллели / К. Пензин // Вестник НАУФОР. 2007. - № 11. - С. 48-55.

10. Максимов Д. М. Пенсионный траст как форма трансграничного накопления и движения капитала в английском праве / Д. М. Максимов // Законодательство и экономика. 2015. - № 12. - С. 57-83.

11. Борисенко Н. Ю. Пенсионное обеспечение : учебник / Н. Ю. Борисенко. - М. : Дашков и $\mathrm{K}^{\circ}, 2009$. - $564 \mathrm{c.}$

12. Габдулхаков Р. Р. Зачем нужны общероссийские неправительственные пенсионные фонды? / Р. Р. Габдулхаков // ЭКО. - 2015. - № 8. - С. 137-150.

\section{Baikal Research Journal}

электронный научный журнал Байкальского государственного университета 


\section{References}

1. Abramov A., Radygin A., Chernova M., Akshentseva K. Efficiency of managing pension assets: theoretical approaches and empiric analyses. Voprosy ekonomiki = Iissues of Economics, 2015, no. 7, pp. 26-44. (In Russian).

2. Timofeyeva A. A. On issue of activities concerning trust management of special-purpose capital. Izvestiya Irkutskoy gosudarstvennoy ekonomicheskoy akademii (Baykalskiy gosudarstvennyy universitet ekonomiki $i$ prava) = Bulletin of Irkutsk State Economics Academy (Baikal State University of Economics and Law), 2015, vol. 6, no. 2. DOI: 10.17150/20720904.2015.6(2).1. (In Russian).

3. Timofeyeva A. On issue of legal limitations in investing pension assets funds. Materialy 68 ezhegodnoi nauchnoi konferentsii professorsko-prepodavatel'skogo sostava i doktorantov, 20-i nauchnoi konferentsii aspirantov i 70-i nauchnoi konferentsii studentov i magistrantov [Materials of 68-th Annual Scientific Conference Faculty and PhD Candidates, 20-th Scientific Conference of PhD Students and 70-th Scientific Conference of Students and Master Degree Students]. Irkutsk, Baikal State University of Economics and Law Publ., 2009. Pr. 1, pp. 238-243.

4. Dmitriyev M. It never pours from emptiness. Vestnik NAUFOR = Bulletin of NAUFOR, 2010, no. 5, pp. 52-54. (In Russian).

5. Lechuk A. L. Why Russia is not Sweden - on issue of pension reform. Pensionnye fondy $i$ investitsii $=$ Pension Funds and Investments, 2008, no. 1, pp. 68-72. (In Russian).

6. Lomtatidze O. V. Problem of protecting private investors' rights in system of regulating financial market. Finansy $i$ kredit $=$ Finance and Credit, 2011, no. 2, pp. 50-55. (In Russian).

7. Khmyz O. Reforming pension fund scheme system in Czeckia. Finansy = Finance, 2010, no. 1, pp. 56-66. (In Russian).

8. Brovchak S. V. Pension fund scheme in Greece and Russia. Finansy $i$ kredit $=$ Finance and Credit, 2011, no. 19, pp. 81-84. (In Russian).

9. Penzin K. Russian-Chinese parallels. Vestnik NAUFOR = Bulletin of NAUFOR, 2007, no. 11, pp. 48-55. (In Russian).

10. Maksimov D. M. Pension trust as a form of cross-border accumulation and movement of capital in English law. Zakonodatel'stvo i ekonomika = Legislation and Economics, 2015, no. 12, pp. 57-83. (In Russian).

11. Borisenko N. Yu. Pensionnoe obespechenie [Pension fund scheme]. Moscow, Dashkov i $\mathrm{K}^{\circ}$ Publ., 2009. 564 p.

12. Gabdulkhakov R. R. Pension Reform in Russia: Finance and Social Aspects. $E K O=E C O$ Journal, 2015, no. 8, pp. 137-150. (In Russian).

\section{Информация об авторе}

Тимофеева Анна Александровна - кандидат экономических наук, доцент, кафедра банковского дела и ценных бумаг, Байкальский государственный университет, 664003, г. Иркутск, ул. Ленина, 11, e-mail: TimofeevaAA@isea.ru.

\section{Author}

Anna A. Timofeyeva - PhD in Economics, Associate Professor, Chair of Banking and Securities, Baikal State University, 11 Lenin St., 664003, Irkutsk, Russian Federation; e-mail: TimofeevaAA@isea.ru.

\section{Библиографическое описание статьи}

Тимофеева А. А. Совершенствование процесса доверительного управления пенсионными накоплениями / А. А. Тимофеева // Baikal Research Journal. - 2016. — T. 7, № 2. - DOI : 10.17150/2411-6262.2016.7(2).4.

\section{Reference to article}

Timofeyeva A. A. Improving the process of trust management of pension assets Baikal Research Journal, 2016, vol. 7, no. 2. DOI: 10.17150/2411-6262.2016.7(2).4. (In Russian).

\section{Baikal Research Journal}

